\title{
An unusual case of uterine leiomyoma vs. hemangiopericytoma: diagnostic dilemma solved by immunohistochemistry
}

\author{
Meena Armo $^{1}$, Kavita Babbar ${ }^{1}$, R. C. Arya ${ }^{2}$ \\ ${ }^{1}$ Department of Obstetrics \& Gynecology, ${ }^{2}$ Department of Pathology, Govt. Chhattisgarh Institute of Medical Sciences \\ (CIMS), Bilaspur, Chhattisgarh- 495001, India
}

Received: 17 August 2013

Accepted: 16 September 2013

\author{
*Correspondence: \\ Dr. Meena Armo, \\ E-mail: drmeenaarmo@gmail.com,priya_d143@yahoo.com
}

(C) 2013 Armo M et al. This is an open-access article distributed under the terms of the Creative Commons Attribution Non-Commercial License, which permits unrestricted non-commercial use, distribution, and reproduction in any medium, provided the original work is properly cited.

\section{ABSTRACT}

Case report of a 45 year, multiparous, widow lady, who underwent total hysterectomy and bilateral salpingooophorectomy for uterine mass of 20 weeks. Microscopic examination revealed a hemangiopericytoma (HPC) of uterus, finally confirmed as uterine leiomyoma with cystic degeneration and HPC-like focal areas without atypia on immunohistochemical staining.

Keywords: Leiomyoma, Hemangiopericytoma, Immunohistochemistry

\section{INTRODUCTION}

A hemangiopericytoma is a rare, distinctive vascular tumor presumably of pericytic origin, exhibits a characteristic well developed "staghorn" branching vascular pattern, which may originates anywhere in the body. The diagnosis of uterine hemangiopericytoma is still a matter of debate, uterine leiomyosarcoma, low grade malignant endometrial stromal sarcoma, highly vascular leiomyomas have been mistakenly identified as HPC. Thus its existence must be proven on the basis of immunohistochemical analysis.

We report here a rare case of uterine leiomyoma having combined features of cystic degeneration and focal areas of 'staghorn' branching vascular pattern mimicking hemangiopericytoma, which is an unusual presentation and not yet reported in the published literature.

\section{CASE REPORT}

A 45-year-old, multiparous, widow lady was referred from remote area, with two ultrasonography reports suggesting complete vesicular mole. She had a history of fullness in lower abdomen and painful heavy menstrual flow since the last 2 years, which were gradually increasing in intensity. On examination uterus was uniformly enlarged to 20 wks size, firm to cystic in consistency. All laboratory tests including serum beta HCG were found within normal range except for the low $\mathrm{Hb}$ level of $8.5 \mathrm{gm} \%$. Ultrasonography revealed an enlarged uterus, $14.25 \times 4.5 \times 12 \mathrm{~cm}$ in size, endometrial cavity distended with multiple anechoic cystic lesions with thinned out uterine parenchyma suggested complete vesicular mole. Both adnexa were normal and no free fluid seen in the pouch of Douglas. Knowing the fact that she would not come for regular follow-ups in the future, total abdominal hysterectomy with bilateral salpingooophorectomy was performed. Patients intraoperative as well as postoperative periods remained uneventful. Gross examination revealed uniformly enlarged uterus, cut section of the specimen exhibited endometrial cavity replaced by multiloculated fluid filled cystic lesions. Histopathological examination revealed combined features of leiomyoma with cystic degeneration and HPC-like focal areas without atypia led to diagnostic 
dilemma, hence forth an immunohistochemical analysis done in which tumor cells showed strong diffusely positivity for smooth muscle actin and focal weak positivity for CD10.

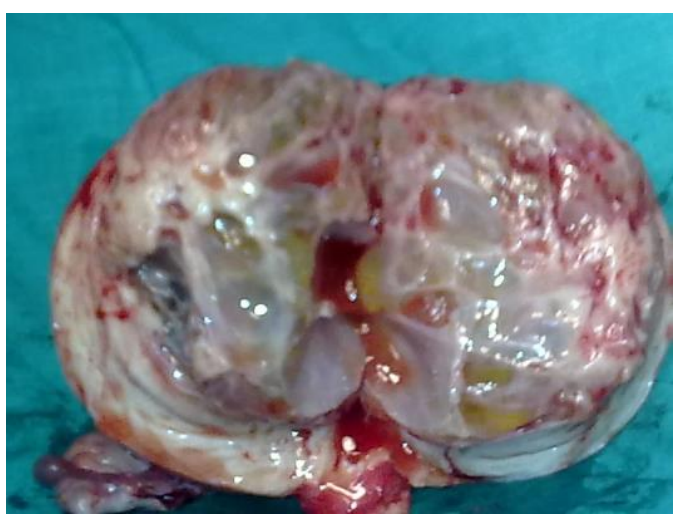

Figure 1: Cut section.

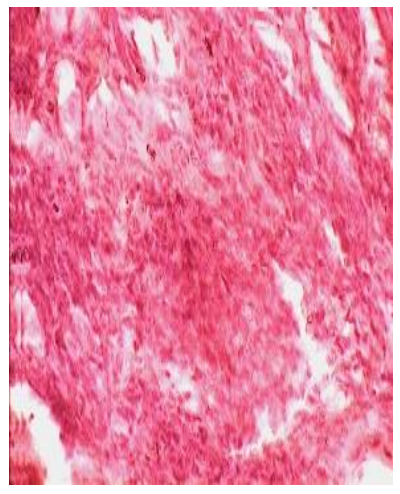

Figure 2: Microscopic picture.

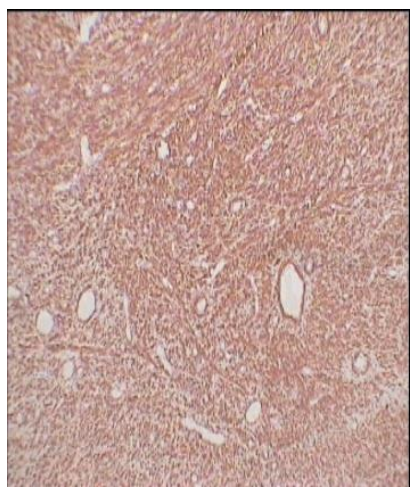

Figure 3: Immunohistochemical staining.

\section{DISCUSSION}

Hemangiopericytoma is an uncommon vascular tumor derived from mesenchymal cells with pericytic differentiation. It was first documented by Stout and Murray in $1942 .{ }^{1}$ Pericytes were $1^{\text {st }}$ described in 1923 by Zimmermann, as specialized cells present around the capillaries, thought to be modified smooth muscle cells. Microscopic characteristics are so-called "pericytoma" pattern with tightly packed cells around ramifying thin walled endothelial-lined vascular channels ranging from "staghorn" configuration to sponge like sinusoidal spaces. It may occur anywhere in the body where capillaries are found. ${ }^{2}$ HPC is currently no longer considered a specific entity but rather as a growth pattern, shared by many, often unrelated neoplasm. About $15 \%$ of soft tissue neoplasms show HPC-like features, at least focally like our case. A uterine hemangiopericytoma is a very rare entity and diagnosis is still a matter of debate. Uterine leiomyosarcoma, or low grade malignant endometrial stromal sarcoma, highly vascular leiomyomas have been mistakenly identified as HPC., 4

Fibroids are the most common benign tumors of the uterus and usually the diagnosis is straightforward. ${ }^{5}$

Our case is unique, because till date in the published literature, there was one case of leiomyosarcoma uterus with HPC-like areas combined with epitheloid differentiation, ${ }^{6}$ however ours is the $1^{\text {st }}$ case of uterine leiomyoma having combined features of cystic degeneration and HPC-like areas as confirmed by immunohistochemistry which showed focal weak positivity for CD10, ${ }^{7,8}$ Hence it is strongly advisable to think about other entities first, when confronted with tumor showing HPC-like features and existence of this must be proven on the basis of classical histology, ultrastructural histology and immunohistochemical analysis. Consent to publish these images has been obtained from the patient.

\section{CONCLUSION}

Uterine hemangiopericytoma have been reported by many authors previously, however ours is the $1^{\text {st }}$ case of uterine leiomyoma having combined features of cystic degeneration and HPC-like vascular pattern. Despite of all, the diagnosis of HPC is still a matter of debate, however microscopy findings supplemented by immunohistochemical staining allow a definite diagnosis and help to differentiate it from other tumors of uterus.

Consent to publish these images has been obtained from the patient.

Funding: No funding sources

Conflict of interest: None declared

Ethical approval: Not required

\section{REFERENCES}

1. Stout AP, Murray MR. Hemangiopericytoma: a vascular tumor featuring Zimmerman's pericytes. Ann Surg.1942; 116:26-33.

2. Enzinger FM, Smith BH. Hemangiopericytoma. An analysis of 106 cases. Human Pathol 1976 Jan; 7(1):61-82.

3. Kauffmann E, Buffin RP, Dabrowski A, DelobelleDeroide A, Lmrabet H. Uterine Hemangiopericytomas. 
Two case reports, J Gynecol Obstet Biol Reprod(Paris) 1995;24(2):149-54

4. Gengler C, Gvillou L. Review Solitary fibrous tumor and hemangiopericytoma evolution of a concept. Histopathology 2006; 48:63-74.

5. Deeksha P, P Priyadarshini, Mirajkar S Feroz, P S Roopa, Ranjini K, Jyothi S, Vani R. Massive degenerated leiomyomas masquerading ovarian neoplasm. Sri Lanka Journal of Obstetrics and Gynaecology2011:33; 163-165.

6. Subramaniam PM, Rekha PR, Thamil Selvi R. An unusual clinical and morphological features of uterine leiomyosarcoma: Immunohistochemistry solves the diagnostic pitfalls of uterine sarcomas.
Journal of Clinical and Diagnostic Research [serial online] 2011 December [cited: 2013 Aug 28]; 5:1653-1655.

7. Rohit B, Jinru S, Amanda JH, Howard TT, Carmen T, Robert A S. Distinction of endometrial stromal sarcomas from hemangiopericytomatous tumors using a panel of immunohistochemical stains. Modern Pathology (2005)18,40-47.

8. Khush M, Robert S, McCluggage W.G. Application of Immunohistochemistry to Gynecologic Pathology. Arch Pathol Lab Med 2008 ; 132 :402-423.

DOI: $10.5455 / 2320-1770 . i j r \operatorname{cog} 20131238$

Cite this article as: Armo M, Babbar K, Arya RC. An unusual case of uterine leiomyoma vs. hemangiopericytoma: diagnostic dilemma solved by immunohistochemistry. Int J Reprod Contracept Obstet Gynecol 2013;2:680-2. 